\section{Geochemical Comparison of REY-rich Deep-sea Deposit from Central Indian Ocean Basin with the Pacific based on Elemental Measurements of Fish Teeth}

\author{
Cai Luyi ${ }^{1}$, Zhang Xiaoyu ${ }^{1,2,3}$, Zhu Kongyang ${ }^{1,4}$, Teng \\ Guochao ${ }^{1}$ \\ ${ }^{1}$ School of Earth Sciences, Zhejiang University, Hangzhou \\ 310027, China \\ ${ }^{2}$ Key Laboratory of Zhejiang Ocean Observation-Imaging \\ Testbed of Zhejiang Province, Zhoushan, 316000, China \\ ${ }^{3}$ Ocean Academy, Zhejiang University, Zhoushan, 316000, \\ China \\ ${ }^{4}$ Key Laboratory of Geoscience Big Data and Deep Resource \\ of Zhejiang Province, School of Earth Sciences, Zhejiang \\ University, Hangzhou 310027, China
}

\section{Introduction}

In recent years, the discovery of rare earths rich deep sea deposits in the Pacific Ocean has attracted wide attentions worldwide. Recent researches has demonstrated the Central Indian Oceanic Basin (CIOB) as potential deposits of rare earths rich deep sea deposits as well, however few systemic comparisons of geochemical characteristics of rare earths rich deep deposit in the CIOB with those from the Pacific Ocean were ever been performed.

In this study, we collected published data from literatures related to geochemical characteristics of rare earths rich deep sea deposits found in the CIOB and the Pacific. The contents, occurrence, $\mathrm{Sr}$ and $\mathrm{Nd}$ isotopic ratios of the fish teeth isolated from three cores sampled form the CIOB, which have been proved as the main carrier of rare earths in these deposits, are measured in this study. The material sources of the rare earths in these deposits are discussed in details. The study will be beneficial to understand the geochemical procedure and enrichment mechanism of the rare earth rich deep sea deposits.

\section{Samples and Methods}

The samples in this study were taken from the caner India Oceanic basin, involving three sedimentary cores with length of $1.4 \mathrm{~m}, 2 \mathrm{~m}$ and $3.4 \mathrm{~m}$ respectively. The three cores are all in uniform texture and reddish brown. Preliminary work has been completed related to the sediment pretreatment, the determination of major elements, trace elements and rare earth elements for the bulk sediments.

The fish teeth are identified and isolated with body microscope and Scanning Electron Microscope, the main elements and minor elements including rare earth elements of fish teeth are analyzed with Electron Probe Microanalysis and Laser Ablation - Inductively Coupled Plasma - Mass Spectrometer respectively. The $\mathrm{Sr}$ and $\mathrm{Nd}$ isotopic composition of fish teeth are analyzed by Mass Spectrum.

\section{Results}

The study indicated that the rare earth rich deep sea deposits in the CIOB and the Pacific are geochemically consistent. The material sources of the sediments have profound impacts to the rare earths enrichment and fractionation.

Acknowledgments: We thank National Natural Science Foundation of China (40706057, 41773005) for financial supports.

References:[1]Rickli J, Frank M, Baker A, et al. 2010. Hafnium and neodymium isotopes in surface waters of the eastern Atlantic Ocean: Implications for sources and inputs of trace metals to the ocean. Geochim Cosmochim Ac, 74: 540557[2]Sa R, Sun X, He G, et al. 2018. Enrichment of rare earth elements in siliceous sediments under slow deposition: A case study of the central North Pacific. Ore Geol Rev, 94: 12-23[3] Stichel T, Frank M, Rickli J, et al. 2012. The hafnium and neodymium isotope composition of seawater in the Atlantic sector of the Southern Ocean. Earth Planet Sc Lett, 317: 282-294[4]Sun P, Deng B, Du G, et al. 2015. Nondestructive rare earth element imaging of fish teeth from deep-sea sediments. X-Ray Spectrometry, 44: 442446[5]Takaya Y, Yasukawa K, Kawasaki T, et al. 2018. The tremendous potential of deep-sea mud as a source of rareearth elements. Scientific Reports, 8: 1-8[6]Watkins R T, Nathan Y, Bremner J M. 1995. Rare earth elements in phosphorite and associated sediment from the Namibian and South African [7]Zimmermann B, Porcelli D, Frank M, et al. 2009. The hafnium isotope composition of Pacific Ocean water. Geochimca et Cosmochimica Acta, 73: 91-101 